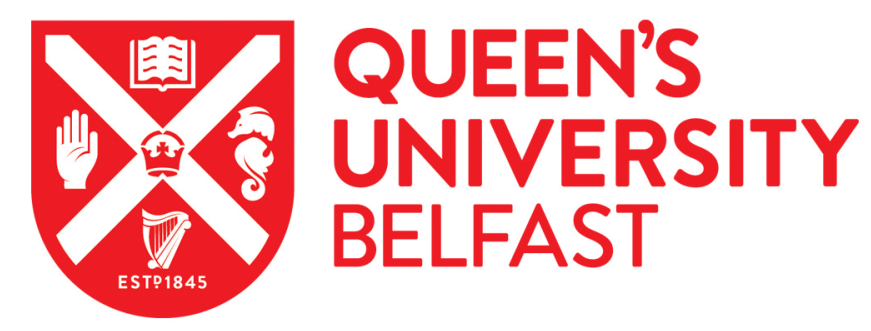

\title{
Peptide nanomaterials for drug delivery applications
}

Pentlavalli, S., Coulter, S., \& Laverty, G. (2020). Peptide nanomaterials for drug delivery applications. Current Protein and Peptide Science, 21(4), 401 - 412. https://doi.org/10.2174/1389203721666200101091834

\author{
Published in: \\ Current Protein and Peptide Science
}

\section{Document Version:}

Peer reviewed version

\section{Queen's University Belfast - Research Portal:}

Link to publication record in Queen's University Belfast Research Portal

\section{Publisher rights}

(c) 2019 Bentham Science Publishers. This work is made available online in accordance with the publisher's policies. Please refer to any applicable terms of use of the publisher.

\section{General rights}

Copyright for the publications made accessible via the Queen's University Belfast Research Portal is retained by the author(s) and / or other copyright owners and it is a condition of accessing these publications that users recognise and abide by the legal requirements associated with these rights.

Take down policy

The Research Portal is Queen's institutional repository that provides access to Queen's research output. Every effort has been made to ensure that content in the Research Portal does not infringe any person's rights, or applicable UK laws. If you discover content in the Research Portal that you believe breaches copyright or violates any law, please contact openaccess@qub.ac.uk. 


\title{
Peptide Nanomaterials for Drug Delivery Applications
}

\author{
Sreekanth Pentlavalli, Sophie Coulter, and Garry Laverty*. \\ Biofunctional Nanomaterials Group, School of Pharmacy, Queen's University Belfast, \\ Medical Biology Centre, 97 Lisburn Road, Belfast, BT9 7BL, Northern Ireland.
}

\begin{abstract}
Self-assembled peptides have been shown to form well-defined nanostructures which display outstanding characteristics for many biomedical applications and especially in controlled drug delivery. Such biomaterials are becoming increasingly popular due to routine, standardized methods of synthesis, high biocompatibility, biodegradability and ease of upscale. Moreover, one can modify the structure at the molecular level to form various nanostructures with a wide range of applications in the field of medicine. Through environmental modifications such as changes in $\mathrm{pH}$ and ionic strength and the introduction of enzymes or light it is possible to trigger self-assembly and design a host of different selfassembled nanostructures. The resulting nanostructures include nanotubes, nanofibers, hydrogels and nanovesicles which all display a diverse range of physico-chemical and mechanical properties. Depending on their design, peptide self-assembling nanostructures can be manufactured with improved biocompatibility and in-vivo stability and the ability to encapsulate drugs with the capacity for sustained drug delivery. These molecules can act as carriers for drug molecules to ferry cargo intracellularly and respond to stimuli changes for both hydrophilic and hydrophobic drugs. This review explores the types of self-assembling nanostructures, the effects of external stimuli on and the mechanisms behind the assembly process, and applications for such technology in drug delivery.
\end{abstract}

Keywords: Peptide, nanomaterials, self-assembly, stimuli, mechanism, drug delivery.

\section{Introduction}

The search for new, more effective drug delivery mechanisms is a fundamental issue of great interest [1]. The limitations of current drug delivery systems include inadequately effective targeting, suboptimal bioavailability, potential cytotoxicity and complicated administration routes and regimens [2]. The aim to improve the pharmacological and therapeutic efficacy of a drug molecule, increase patient convenience and reduce side effects using traditional drug delivery systems proves a challenge to the pharmaceutical industry [3].

Peptides are essentially 'building blocks' of the human body's proteins, which are imperative for normal functioning of the immune system, cellular signaling and the formation of new tissue, skin and hormones. They have proven antimicrobial properties due to an optimal hydrophobic/charge balance that exists within their primary structure and they exist as defensive weapons against infection throughout nature [4]. They fight infections using self-assembly, which is a natural process where the body creates potent membrane-targeting antimicrobial peptides as part of an innate immune response [5].

Self-assembly is defined by the spontaneous diffusion and specific association of molecules controlled by non-covalent interactions [6]. Self-assembling peptides are exciting leads for novel biocidal agents in modern society where traditional antibiotics are under immense pressure from emerging pathogenic bacterial resistance and successes in antibiotic research and development deteriorate [7]. 
Peptides are made from several amino acids (monomers) that have been joined via a condensation reaction. Amino acids contain an amine group $(\mathrm{N})$, a carboxylic acid group ($\mathrm{C}=\mathrm{O}$ ) and an ' $\mathrm{R}$ ' (aliphatic or aromatic) side chain, that can have numerous physiochemical functionalities which mean that the function of the peptide sequence can be tailored as per demand depending on the side chains incorporated. Depending on the nature of side chain, amino acids can be hydrophobic, hydrophilic or charged (basic or acidic) [8]. There are twenty naturally occurring amino acids with versatile properties that can be used to synthesise a plethora of different peptide sequences. Peptide sequence design plays a key role in its usage. Variation of the amino acids incorporated in the sequence can be used to develop self-assembled systems. Self-assembly occurs when the interactions of attraction and repulsion within a molecule alter a disordered system into one that is more ordered, using a 'bottom-up' approach [9]. This process is known to occur in nature, for example, in the assembly of cell membranes by phospholipids for the development of a bilayer, and in DNA double helix production. Self-assembly is reliant on non-covalent interactions, such as hydrogen bonds, Van der Waals forces, electrostatic interactions and hydrophobic and hydrophilic interactions $[10,11]$.

Recently many self-assembling nanostructure systems have been synthesized from biomaterials like carbohydrates, nucleic acids, and peptides for various biomedical applications such as tissue engineering, drug delivery and in the development of biosensors. Self-assembling peptides remain the most promising soft biomaterial due to following reasons:

(i) Peptides can be synthesized using well-established, routine solid-phase synthesis methods affording high yields and the synthesis process itself enables sequence-specific modifications at the molecular level [12].

(ii) Further functionalization of peptides can be achieved by simple addition of compounds such as drugs, antibodies, enzymes, magnetic particles and fluorescent compounds for visualization of the peptide structure [13].

(iii) Naturally occurring self-assembly motifs present in proteins such as $\alpha$-helices, $\beta$-sheets, and coiled coils can be used to derive the self-assembly process [14].

(iv) The main signaling language in the extracellular matrix (ECM) is mediated via peptide epitopes which is the main advantage of peptide biomaterials in regenerative scaffolds [15].

(v) The charge on the peptide helps to carry drugs across cell membranes and enables the translocation of genes inside the nucleus [16].

There are many physiological factors that can affect the stability and self-assembly of peptides. Changes in the environmental conditions can be harnessed to offer control over the formation of nanostructures with the desired characteristics being developed according to the preferred function, such as drug delivery. Stimuli which can be used to drive the selfassembly process include $\mathrm{pH}$, ionic strength, temperature and specific enzyme availability [17]. Substances that contain hydrophobic tails and hydrophilic heads, such as phospholipids, will aggregate in aqueous environments. Hydrophobic interactions within the peptide sequence and hydrophilic interactions between the aqueous environment and the peptide will promote the self- assembling process $[17,18]$. Dehsorkhi and co-workers (2013) studied the effect of changing the $\mathrm{pH}$ on the assembly process of a peptide amphiphile and found that under different $\mathrm{pH}$ values, different structures were produced, including flat and twisted structures. This demonstrates the importance of $\mathrm{pH}$ and provides opportunities for producing various polymorphic structures of the same molecule by altering the conditions in which it is made to assemble [18]. Temperature was also shown to affect the structures formed during self-assembly. At low temperatures hydrogen bonding increased the stability of the $\beta$-sheet, whereas at higher temperatures, hydrogen bonding was disturbed [9]. 


\section{SELF-ASSEMBLED PEPTIDES}

Self-assembled peptides have been of great interest due to their biocompatibility in vivo, the wide variety of products that can be formed for numerous functions and the biodegradable nature of the peptides. It is relatively cheap to synthesize peptides if they are ultrashort, that is, less than seven amino acids in length which means such sequence lengths are more attractive for upscale. Ultrashort sequences can be used to construct numerous nanostructures, including nanotubes, hydrogels and nanofibers, as shown in Figure 1, which are all in the nanometer scale of $1 \times 10^{-9} \mathrm{~m}$. Different types of peptides such as dipeptides, cyclic peptides, amphiphilic peptides, $\alpha$-helical peptides and $\beta$-sheet peptides have been utilized as self-assembled nanostructures [19]. Each of these has great potential in drug delivery to treat several different conditions including cancer, infections and wounds.

\subsection{Nanotubes}

Nanotubes are a type of nanostructure that are formed with a definite hollow centre. As the name suggests, they are long tube-like materials [20]. There are numerous types of nanotubes which can each be used for various functions. In 1993, Ghadiri et al. reported the production of nanotubes [21]. Cyclic peptides were used and the D- and L- form of amino acids in these peptides were interchanged. A planar ring was formed, protonated and crystallised and by the process of self-assembly a cyclic peptide nanotube was formed. This self-assembly was controlled by the acidic environment which formed the ordered, tightly packed nanotube. This type of nanotube showed great potential due to the simplicity associated with changing its structure, for example, changing the side chains on the amino acids would change the functionality and therefore the potential application of the nanotube. Ghadiri and researchers (2001) found that when this structure formed hydrogen bonds, the cyclic peptides stacked to form the characteristic $\beta$-like tube structures with the internal hole. The antibacterial properties of cyclic D, L- $\alpha$-peptides were examined for selective targeting and self-assembly in the membranes of bacteria [22]. These peptides increased the membrane permeability, eradicating ion potentials and eventually caused cell death. This research highlighted the potential of cyclic peptides to be used clinically in the treatment of bacterial infections. One example of cyclic peptide nanotube used clinically today is lanreotide. This is a synthetic hormone of somatostatin, which is a growth hormone-inhibiting hormone used in the treatment of acromegaly and can be administered both intramuscularly and subcutaneously to patients [23]. It is an octapeptide salt which self-assembles when in water by hydrophobic and aromatic bonding, to form a well-ordered nanotube structure [3]. Amyloid fibrils are aggregates of peptides or proteins that can cause neurotoxicity. They are implicated in numerous conditions, such as Alzheimer's disease and Parkinson's disease [24, 25]. These aggregates are insoluble, resist degradation and have a distinctive $\beta$-sheet conformation which led to the examination into their potential application in the field of nanotechnology [26]. As shown by Rambaran et al. (2008), A $\beta$ amyloid protein plaques known to be involved in Alzheimer's disease could be made to form amyloid-like fibrils. Gazit and co-workers (2003) found that diphenylalanine, which is the shortest core recognition motif for the Alzheimer's $\beta$-amyloid polypeptide, can self- assemble into nanotubes [27]. It was found that these nanotubes were hollow, stiff and have a long persistence length. The stability of these nanostructures enables their use in long term nanodevices, such as biosensors, which transform a biological component into an electrical signal that can be analysed [28]. Amphiphiles are molecules that have both hydrophilic and hydrophobic properties, for example, a hydrophobic tail and hydrophilic head in which the peptide is located. Peptide amphiphiles are considered a very prosperous structure as under certain physiological 
conditions they can self-assemble to form well-ordered nanostructures, including nanotubes. Hamley et al. (2013) found that temperature and $\mathrm{pH}$ can affect which nanostructure is formed [29]. It was observed that at room temperature and under aqueous conditions nanotubes are formed, but at higher temperatures of $55^{\circ} \mathrm{C}$, twisted tapes are formed. These nanotubes have the potential of releasing encapsulated products which could be used in drug delivery.

\subsection{Nanofibers}

Nanofibers differ from nanotubes in the that they lack the hollow central pore. Peptide amphiphiles have the ability to self-assemble and by the process of micellization, the formation of $\beta$-sheets and micelles joining together, cylindrical nanofiber structures can be formed [30]. An example of this is the peptide, RAD16-II-AcetylN-(RA- RADADA) ${ }_{2}-\mathrm{CNH}_{2}$, which is being tested for use in myocardial infarction [3]. Self-assembling peptides that form nanofibers are preferred to carbon nanofibers, as the manufacturing costs are considerably lower making these more suitable for large scale production. In addition, peptide nanofibers are considered more biocompatible and modifications can be made at the molecular level, as previously mentioned, thereby tailoring the sequence which can result in many variations and uses. Nanofibers have the capacity to form hydrogels by entrapping solvent molecules within the three-dimensional matrix formed by the nanofiber structure.

\subsection{Hydrogels}

Self-assembling peptides can form hydrogels which could be used for drug delivery. They possess the ability to form or break down in response to specific stimuli, allowing for selective targeting. Peptides that have $\alpha$-helical, $\beta$-helical and amphiphilic properties can selfassemble to form hydrogels. In addition, it has been found that certain soluble peptides can form a $\beta$-hairpin under physiological ionic strength and $\mathrm{pH}$, to self-assemble into rigid and stable hydrogels. Using peptides to form hydrogels is ideal since it enables alterations of the molecular structure to vary the final hydrogel product and therefore it's function $[31,32]$. Octreotide, like lanreotide, is used clinically to treat growth hormone hypersecretory conditions and forms a hydrogel when administered subcutaneously [3]. When at a physiological $\mathrm{pH}$ of 7.4 , $\beta$-hairpin structures are formed which can assemble into a supramolecular hydrogel [3]. Bing Xu (2011) discusses possible applications of selfassembling hydrogels [33]. Additionally, McCloskey et al. (2016) examined the antimicrobial and anti-inflammatory effects of non-steroidal anti-inflammatory drug (NSAID)-conjugated ultrashort cationic self-assembled peptide hydrogels. It was found that these hydrogels showed potential for the treatment of chronically infected wounds, where major inflammation as a result of infection was prolonging the healing process and that they could also be valuable in preventing antibiotic resistance [34].

\subsection{Nanovesicles}

Self-assembled peptides can form nanovesicles when in aqueous environments. Song (2005) found that when nanotubes were diluted by adding $0.1 \mathrm{~mL}$ of water at physiological $\mathrm{pH}$, the nanotubes which were previously formed transitioned into nanovesicles [35]. Yan et al. (2007) used this feature to observe delivery into cells (36). Nanovesicles could be used to encapsulate drugs and deliver their cargo to target sites, for example intracellularly, for therapeutic effect.

\subsection{Dipeptides}

Short chain peptides are gaining interest as viable self-assembled nanostructures for various biomedical applications including drug delivery [37, 38]. Dipeptides have been studied extensively for drug delivery applications. The first reported dipeptide 
diphenylalanine, Phe-Phe (FF), which has been used for the self-assembly of different nanostructures, is a core motif of the amyloid- $\beta$ polypeptide segment used to drive selfassembly in Alzheimer's disease [39]. Many research groups have been developing selfassembling FF dipeptides into nanostructures such as nanoparticles, nanotubes, nanovesicles and nanowires as shown in Figure 2 [40-45].

The unique property of FF nanotubes is thermal stability, high yield and controlled length of the tube which is dependent on monomer concentration $[41,46]$. There are several other short linear peptides which can form self-assembled nanostructures for biomedical applications, especially drug delivery $[47,48]$. For instance, KLVFF, a short peptide derived from the amyloid- $\beta$ peptide self-assembly mechanism could also self-assemble into nanofibrous structures and then hydrogel forms in a concentrated phosphate buffered saline solution. The physical and chemical characterisation of linear short peptides indicates that self-assemble of short peptides changes into $\beta$-sheet structures and then form nanofibrillar hydrogel structures through electrostatic interactions [47]. Other short linear peptides like DFNK and DFNKF have both been shown to form self-assembled nanofibril structures depending on the $\mathrm{pH}$ of the solution. These peptide sequences have both aromatic rings and charged side chains which help to drive the assembly process to form nanostructures [48].

\subsection{Cyclic peptides}

The first cyclic peptides were developed by altering D- and L- form amino acids in peptide sequences that could self-assemble into nanotubes [49]. However, in 1993, the first cyclic peptide nanotube was developed using same theory [21]. The basic principle behind cyclic peptide self-assembly is through aggregating cyclic peptides as building blocks where the amino and carbonyl groups are arranged perpendicular to the ring [50]. Also, by altering D- and L- type amino acids in the peptide sequence, the peptide side chains can be arranged on the outside of the ring which can create nanotube structures which are stabilized by hydrogen bonding [51]. In comparison with other self-assembling nanotubes, cyclic peptide self-assembled nanotubes have several distinct advantages such as the precise diameter of the structure is dependent on the length of peptide chain employed which enables the user to design the sequence for different applications. For example, if you increase the peptide length from 4 amino acids to 12 amino acids, the internal diameter of cyclic peptide changes from 2 ${ }^{\circ} \mathrm{A}$ to $13{ }^{\circ} \mathrm{A}[52,53]$. Moreover, by varying formulation parameters cyclic self-assembled nanotubes can convert to self-assembled nanoparticles as shown in below Figure 3 [54].

\section{7. $\alpha$-Helical peptides}

It has been well documented that biological and physical properties can enhance the selfassembly of peptides into helical structures. $\alpha$-helical peptides have particularly attracted the attention of researchers mainly due to the ability to form nanostructures that are akin to the cytoskeleton and extracellular matrix in biological systems [55]. For instance, peptides which are 25-50 amino acids length can form $\alpha$-helical peptides [56] and these $\alpha$-helical peptides with 2-5 helices can aggregate around each other to form nanofibers [57, 58]. Hydrogels with coiled-coil blocks could also be self-assembled from helical peptides with triblock motifs [59]. $\alpha$-helices can form by altering repeated hydrophobic and charged amino-acids in the sequence via coiled-coil structures [60]. Moreover, the hydrogel properties can be tuned by varying the length and structure of the basic coiled-coil units [61]. Therefore, these materials could be used as potential controlled drug delivery devices.

\section{8. $\beta$-Sheet peptides}


The $\beta$-sheet conformation is one of the most common motifs that can be used for peptide self-assembly [62]. It consists of alternating hydrophilic and hydrophobic amino acid units in the peptide sequence, which can provide amphiphilic properties that drive the formation of self-assembled $\beta$-sheets [63]. These $\beta$-sheets may be formulated into various nanostructures such as nanotubes, nanoribbons and monolayers in the nanoscale range [64-68]. For example, the $\beta$-sheet peptide QQRFEWEFEQQ can self-assemble to form a $\mathrm{pH}$ responsive hydrogel using peptide ionizable side chains from glutamine and arginine amino acids. These peptides are soluble in neutral $\mathrm{pH}$ conditions and transform to a hydrogel structure under low $\mathrm{pH}$ conditions [64].

\section{FACTORS THAT CONTROL SELF-ASSEMBLY}

One of the major challenges in self-assembly is the ability to control the process itself. Many of the systems that self-assemble suffer from the issue that once the material is placed into water or buffer, the self-assembly process is initiated immediately and is therefore poorly controlled [69]. Due to this, there has been considerable interest in developing methods that are in command of the assembly process. There are many ways to drive the self-assembly process, which include changes in $\mathrm{pH}$ and ionic strength, enzymatic triggers and light, each of which are discussed in more detail.

\section{1. pH/Ionic strength}

One approach to directly control the self-assembly process of peptide systems is by the application of a $\mathrm{pH}$ switch [64]. $\mathrm{pH}$ switching offers a way of directly controlling the selfassembly of monomeric peptides, while avoiding any structural traps. Additionally, it provides a pathway for encapsulation and controlled release of large biomolecules from the resultant structures [64]. A pH switch can be introduced by the incorporation of either complimentary or opposed charges in the peptide design [70]. Aggeli et al. studied how the incorporation of glutamic acid (Glu) or ornithine (Orn) into the primary structure of a peptide can lead to the reversible control of self-assembly by altering the $\mathrm{pH}$. They discovered that self-assembly could be controlled by appropriately incorporating these side chains, which resulted in the peptide-peptide free energy of interactions being directly affected by electrostatic forces between $y-\mathrm{COO}-$ in Glu- or $\delta-\mathrm{NH}+$ in Orn + . Therefore, self-assembly could be smoothly and continuously altered by varying the $\mathrm{pH}$. By increasing the $\mathrm{pH}$ the peptide could be switched from its supramolecular to monomeric state with the converse happening when the $\mathrm{pH}$ was decreased [64].

\subsection{Enzymes}

One of the more challenging aspects in molecular self-assembly is the ability to control the self-assembly of nanostructures under physiological reaction conditions. The design of peptide structures that are responsive to enzymes is an area that has attracted considerable interest. Enzyme-assisted nanofabrication can be achieved by catalysing the synthesis of a self-assembled molecule, or by removing a blocking group from a molecule to permit nanofabrication [71]. Enzyme-assisted self-assembly can take place via reverse hydrolysis, which involves a protease driving the assembly of peptide hydrogelators by coupling of nonassembling precursors. Ulijn and Smith discussed the use of Fmoc-amino acids to synthesize Fmoc-tripeptide derivatives. This reaction is a fully reversible pathway which plays an important role in controlling the self-assembly process and has been applied in wound care and biosensing [72].

\subsection{Light}


In this method an external stimulus i.e. light is used to drive the self-assembly process. Light provides a non-invasive stimulus to trigger the process. To facilitate the self-assembly process Cui et al. incorporated a photo acid generator (PAG) into liposomes which acted to lower the $\mathrm{pH}$ upon exposure to light. This was a successful approach in triggering the selfassembly of peptides by light activation within a spatially confined acidic environment [73]. Schneider and Pochan have also developed a light triggered $\beta$-hairpin system wherein a cysteine residue was introduced into the hydrophobic face of the peptide and a 'photo cage' ( $\alpha$-carboxy-2-nitrobenzyl) was then attached to this cysteine. Self-assembly was controlled since the 'photo cage' prevented the folding of the peptide into a $\beta$-hairpin structure until exposed to UV light which resulted in 'de-caging' and enabled the self-assembly of the peptide [74]. Using light to drive the assembly process has the advantage that it does not perturb the solution but interacts with the material, this means that it does not cause localized changes in the environment [52].

\section{MECHANISMS OF SELF-ASSEMBLY}

The key contributors to peptide self-assembly include hydrogen bonding, $\pi$ - $\pi$ stacking, electrostatic interactions and hydrophobic interactions. The nature of the interactions is dependent on the amino acids incorporated in the sequence, for example, non-polar amino acids (aromatic or aliphatic) are responsible for hydrophobic aggregation through $\pi-\pi$ stacking and hydrophobic interactions whereas polar amino acids generate either electrostatic or hydrogen bonding depending on the charge on the residues [75].

\subsection{Electrostatic interactions}

The attractive and repulsive forces between charged residues on amino acids or sometimes those between the amino acid side chains and drugs result in electrostatic interactions within the peptide self-assembly processes. After assembly, they form stable nanostructures that could be used for various applications such as drug delivery and tissue engineering. For instance, a multifunctional peptide self-assembly nanostructure was designed and formulated using RALA/pDNA or RALA-bisphosphonates cell-penetrating peptide nanoparticles through electrostatic interactions. These nanoparticles have been used for the condensation of DNA or bisphosphonate material into nanoparticulate form and have demonstrated successful delivery of this cargo intracellularly $[76,77]$.

\subsection{Hydrophobic interactions}

One of the most important effects among non-covalent interactions in the peptide selfassembly process is hydrophobic interactions. Amphiphilic peptides can be readily harnessed because of the coexistence of both hydrophobic and hydrophilic regions within the peptide sequence. In general, under polar conditions, the hydrophobic units collapse and cluster together to hide from water, meanwhile the hydrophilic region expands to interact with water $[78,79]$. For instance, amphiphilic drugs composed of a tau protein derived peptide conjugated to the hydrophobic anticancer drug camptothecin were used to generate a fibril structure through hydrophobic interactions and intermolecular hydrogen bonding [80].

\subsection{Hydrogen bonding}

Hydrogen bonding is the electrostatic attraction between hydrogen atoms and nearby highly electronegative atoms such as nitrogen and oxygen atoms. Most self-assembling peptide sequences to date have been designed based on naturally occurring hydrogen bonding patterns which can be found in $\alpha$-helices, $\beta$-sheets, and coiled coils. Hydrogen bonding plays an important role in the formation and stabilization of the secondary structure of the peptide and protein folding. The interaction between amide and carbonyl groups of the peptide back 
bone increases the stability of peptide self-assembly. Based on that, $\beta$-sheet structure formation is either parallel or antiparallel in nature depending on the peptide sequence directions. Usually self-assembling peptide sequences consist of repeating units of amino acids containing both hydrophobic and hydrophilic regions which will orientate themselves within the self-assembled nanostructure depending on surrounding environment. For example, in aqueous media, hydrophobic regions will be buried inside the structure to enable the hydrophilic regions to interact with the surrounding aqueous system [81]. Whereas in $\alpha$ helices the individual peptide chains form intramolecular hydrogen bonds with backbone amide components. In this arrangement, side chains from the amino acids present on the surface of each helix and further facilitate the accessibility of them in the solvent.

\section{4. $\pi-\pi$ Stacking}

$\pi-\pi$ stacking can encourage the peptide self-assembly process and directional growth for peptide sequences containing aromatic groups. $\pi-\pi$ stacking is very robust in water due to solubility [82]. Whereas in organic solvents only toluene and trifluoroacetic acid show more distinct advantages for forming $\pi-\pi$ stacking [43]. For example, in the FF dipeptide selfassembly process, $\pi-\pi$ stacking and hydrogen bonding of aromatic groups stabilizes the selfassembled nanostructure which has been demonstrated in various drug delivery applications $[46,83]$.

In the overall self-assembly process these non-covalent interactions play a vital role. Also, these interactions may vary in strength and nature depending on the external stimuli applied such as $\mathrm{pH}$, temperature and solvent polarity which are all capable of triggering selfassembly and the development of the final nanostructure. Especially when charged amino acids are incorporated within the sequence such as glutamic acid, lysine, aspartic acid, histidine and arginine it is important that a controlled $\mathrm{pH}$ environment is used to trigger the assembly process for consistent results [54]. For drug delivery the physical and biological properties of peptide nanostructures play an important role in their successful application. One should consider, while designing the peptide sequence for self-assembled nanostructures for drug delivery, the nature of non-covalent interactions as well as peptide types and structures.

\section{SELF-ASSEMBLED PEPTIDE NANOSTRUCTURES FOR DRUG DELIVERY}

The nanotechnology revolution has led to the introduction of a range of different nanomaterials for drug delivery. In particular, the use of peptide-based nanomaterials has received interest due to the inherent merits of such structures, as discussed in this review, including chemical versatility, biocompatibility, biodegradability, self-assembly and tunable immunogenicity [84]. These advantages have generated significant interest in the field of drug delivery with peptides being utilized as functional components and novel singular agents in a range of different applications including as therapeutics for cancer, HIV and wound healing $[34,85,86]$. A range of peptide sequence lengths have been investigated within the context of drug delivery with long sequences through to dipeptides demonstrating potential.

\subsection{Anticancer drug delivery}

Cancer is the second leading cause of death globally and was responsible for an estimated 9.6 million deaths worldwide in 2018 [87]. Conventional chemotherapy remains the cornerstone of treatment, however, non-specific distribution in vivo often leads to severe and debilitating side effects. Nano-based therapeutics are gaining momentum within the field of anticancer therapeutics boasting increased targeting ability and therefore reduced systemic side effects, high drug loading capacity and improved stability [88]. There are already several 
peptide therapeutics in use for the treatment of cancer including buserelin and goserelin employed in the treatment of prostate and breast cancers [89]. Self-assembling peptide nanostructures have attracted significant attention in the field of anticancer therapeutics. This is largely due to the ability to self-assemble to form a range of structures, for example, nanotubes, nanovesicles and nanofibers to generate hydrogels, each suitable for the delivery of a specific anticancer agent [90]. To date, several self-assembling peptide structures have been employed to deliver anticancer agents such as doxorubicin, paclitaxel and curcumin with investigations entering both preclinical and clinical studies [91-93]. Recent notable advances in the area of anticancer drug delivery includes using peptides as active therapeutics. For example, the Xu group presented the ultrashort sequence NapFF which could selectivity inhibit the growth of glioblastoma cells via nanofiber formation which resulted in disruption of microtubules and tubulins [94]. In addition to this, a greater understanding of self-assembly process itself has enabled the development of novel therapeutics with enzymatic self-assembly triggers. The Xu group demonstrated the use of enzyme-instructed intracellular self-assembly to enhance the activity of cisplatin in drugresistant ovarian cancer. Ultrashort peptide precursors were designed as the substrates of the enzyme carboxylesterase. This enzyme cleaved the precursor to enable peptide self-assembly into nanofibers. The precursor was demonstrated to be innocuous to normal cells yet doubled the activity of cisplatin against drug resistant ovarian cancer cells [95]. This work illustrates the shift in the field of chemotherapeutic drug delivery which aims to harness simple, yet novel mechanisms to introduce cytotoxic components without increasing the systemic burden or side effects.

\subsection{Targeted drug delivery}

Targeted drug delivery refers to therapeutic agents which, upon administration, have the capacity to specifically transport to the required site of action [96]. Such delivery can overcome the issues with non-specificity of traditional therapeutics. Cell-penetrating peptides are cationic in nature and typically comprise less than thirty amino acids and are often employed to circumvent the cell membrane thereby facilitating targeted drug or gene delivery [96]. Work by Boekhoven and colleagues described the use of microparticles with a doxorubicin conjugated alginate core and a shell of peptide amphiphile nanofibers functionalised to target the folate receptor and demonstrated a 60-fold higher cytotoxicity against MDA-MB-231 breast cancer cells in vitro compared to non-targeting particles [97]. A significant advantage of using self-assembling peptides in this manner is the scope to produce a range of different nanostructures to enable highly specific targeting and the ability to chemically or physically conjugate various drugs to offer several different therapeutic applications using the same technology.

\subsection{Stimuli-responsive drug delivery}

The ability to trigger the self-assembly process in response to a range of physiological stimuli has significant benefits for both controlled and targeted drug delivery. Hydrogels are gaining recognition as a class of therapeutics within this area since the stimuli-responsive nature of the assembly process enables 'programmable' release of therapeutics [98]. Indeed, the formation of the three-dimensional fibrous network can entrap the active therapeutic thereby controlling the rate of release. The process of self-assembly eliminates the need for toxic cross-linking agents commonly required to produce hydrogels composed of polymers [90]. One example of this is the ability to use injectable hydrogel formulations which can be inserted in direct contact with tumour tissue in order to provide a local effect thereby reducing toxicity and improving efficacy of cancer therapeutics. Yishay-Safranchik et al. developed an injectable in situ forming hydrogel based on the self-assembling peptide motif 
KLD to control delivery of doxorubicin or a pro-apoptotic peptide for localised cancer treatment. At higher peptide concentrations self-assembly was achieved within seconds and the hydrogel network was demonstrated to be effective at controlling the release of both therapeutic agents and inhibiting tumour cell growth in vitro [99]. This study demonstrates the potential for stimuli responsive drug delivery and highlights the advantages to such technology including the ability to achieve depot formation at the tumour site without surgery, simple drug loading and no requirement for organic solvents. It is possible to physically encapsulate or chemically conjugate drugs within the hydrogel matrix. Studies have been conducted by various groups within this field including the $\mathrm{Xu}$ group who have introduced a range of supramolecular hydrogels with chemically conjugated drugs which demonstrate favourable release profiles [100].

\section{CONCLUSIONS}

There is increasing demand for efficiently designed, controlled and biodegradable delivery systems to target release for therapeutics with reduced side effects. A major advantage of using self-assembled peptide delivery systems is that the carrier itself can act as a therapeutic enabling the development of a 'one design, one carrier' motif with multiple functionalities including targeted delivery, cell penetration, endosomal escape motifs, release-responsive characteristics and efficient binding with therapeutic payloads. Many peptides have been studied both in in vitro and in vivo model systems for a range of biological medical targets as building blocks in nanomedical applications. Also, peptide self-assembling systems are biocompatible, responsive to environmental changes and possess the ability to be conjugated with targeted drugs for various drug delivery applications. However, some key studies still need to be performed and factors developed before commencing clinical studies such as the ability to precisely control size during formulation, stability and investigations into the prolonged effect on cells. Changes in fabrication parameters or the use of templates will improve formulated self-assembled peptides size and provide more consistent results. Peptides have been synthesized mainly via the routes of recombinant technology and solid phase chemical methods. Even small scale GMP grade synthesis by fermentation of a recombinant technology costs around US\$ 1 million. Still the manufacturing method of choice for peptide production is solid-phase synthesis. Some other challenges to upscale include synthesis on a large scale, efficient purification, and achieving high yields. In the future, peptides could act as "add-ons" for other pharmaceutical agents to direct them to their targets, carry them across the cell membrane and improve biological action. In conclusion,

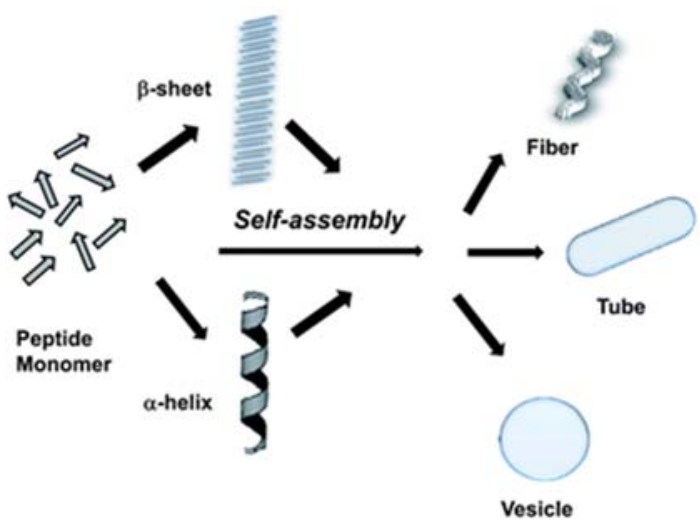
we anticipate that with multi-disciplinary efforts, peptide self-assembled nanostructures have much potential for drug delivery applications and present a promising route to treat human diseases. 
Figure 1. Various forms of self-assembled peptides. Reproduced from J.J. Panda et. al. with permission from the Royal Society of Chemistry [19].

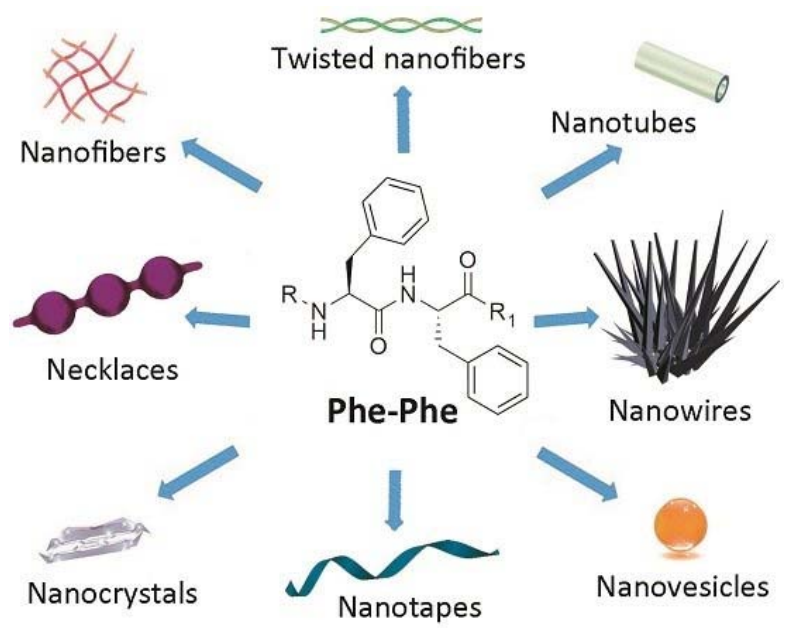

Figure 2. Various nanostructures formed as a result of self-assembly of the dipeptide FF. Reproduced from Marchesan et al. with permission from the Creative Commons Attribution License [40].

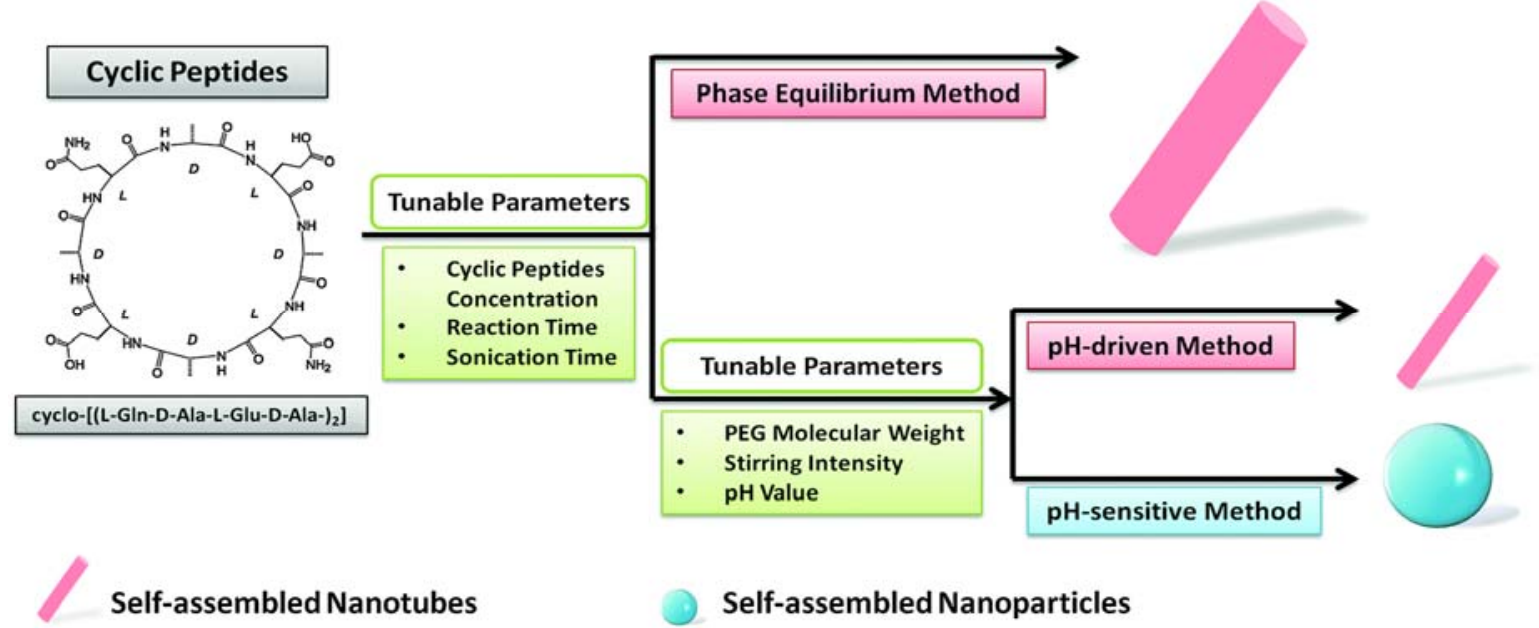

Figure 3. Schematic of the eight-residue cyclic peptide cyclo-[(L-Gln-D-Ala-L-Gu-D-Ala-)2] and the tunable parameters responsible for its self-assembly to form nanotubes and nanoparticles. Reproduction from Sun et al. with permission from the Royal Society of Chemistry [54].

\section{REFERENCES}

[1] Bianco, A.; Kostarelos, K.; Prato M. Applications of carbon nanotubes in drug delivery. Curr. Opin. Chem. Biol., 2005, 9(6), 674-679.

[2] Goldberg, M.; Langer, R.; Jia, X. Nanostructured materials for applications in drug delivery and tissue engineering. J. Biomater. Sci. Polym. Ed., 2007, 18(3), 241-268.

[3] Rafferty, J.; Nagaraj, H.; McCloskey, A.P.; Huwaitat, R.; Porter, S.; Albadr, A.; Laverty, G. Peptide therapeutics and the pharmaceutical industry: barriers encountered translating from the laboratory to patients. Curr. Med. Chem., 2016, 23(37), 4231-4259. 
[4] Laverty, G.; McCloskey, A.P.; Gilmore, B.F.; Jones, D.S.; Zhou, J.; Xu, B. Ultrashort cationic naphthalene-derived self-assembled peptides as antimicrobial nanomaterials. Biomacromolecules, 2014, 15(9), 3429-3439.

[5] Schnaider, L.; Brahmachari, S.; Schmidt, N.W.; Mensa, B.; Shaham-Niv, S.; Bychenko, D.; Adler-Abramovich, L.; Shimon, L.J.W.; Kolusheva, S.; DeGrado, W.F.; Gazit, E. Self-assembling dipeptide antibacterial nanostructures with membrane disrupting activity. Nat. Commun., 2017, 8(1), 1365.

[6] Valéry, C.; Pouget, E.; Pandit, A.; Verbavatz, J.; Bordes, L.; Boisdé, I.; Cherif-Cheikh, R.; Artzner, F.; Paternostre, M. Molecular origin of the self-assembly of lanreotide into nanotubes: a mutational approach. Biophys. J., 2008, 94(5), 1782-1795.

[7] averty, G.; Gorman, S.P.; Gilmore, B.F. The potential of antimicrobial peptides as biocides. Int. J. Mol. Sci., 2011, 12(10), 6566-6596.

[8] McCloskey, A.P.; Gilmore, B.F.; Laverty, G. Evolution of antimicrobial peptides to self-assembled peptides for biomaterial applications. Pathogens., 2014, 3(4), 791-821.

[9] Mandal, D.; Shirazi, A.N.; Parang, K. Self-assembly of peptides to nanostructures. Org. Biomol. Chem., 2014, 12(22), 3544-3561.

[10] Hosseinkhani, H.; Hong, P.; Yu, D. Self-Assembled proteins and peptides for regenerative medicine. Chem. Rev., 2013, 113(7), 4837-4861.

[11] Yan, X.; Zhu, P.; Li, J. Self-assembly and application of diphenylalanine-based nanostructures. Chem. Soc. Rev., 2010, 39(6), 1877-1890.

[12] Rubert Pérez, C.M.; Stephanopoulos, N.; Sur, S.; Lee, S.S.; Newcomb, C.; Stupp, S.I. The Powerful Functions of Peptide-Based Bioactive Matrices for Regenerative Medicine. Ann. Biomed. Eng., 2015, 43(3), 501-514.

[13] Castillo, J.; Andersen, K.B.; Svendsen, W.E. Biomaterials Science and Engineering InTech. Self-assembled peptide nanostructures for biomedical applications: advantages and challenges., 1st ed.; Rosario Pignatello: 2011.

[14] Matson, J.B.; Zha, R.H.; Stupp, S.I. Peptide self-assembly for crafting functional biological materials. Curr. Opin. Solid St. M., 2011, 15(6), 225-235.

[15] Kokkoli, E.; Mardilovich, A.; Wedekind, A.; Rexeisen, E.L.; Garg, A.; Craig, J.A. Self-assembly and applications of biomimetic and bioactive peptide-amphiphiles. Soft Matter, 2006, 2(12), 1015-1024.

[16] Pujals, S.; Fernández-Carneado, J.; López-Iglesias, C.; Kogan, M.J.; Giralt, E. Mechanistic aspects of CPP-mediated intracellular drug delivery: Relevance of CPP self-assembly. Biochim. Biophys. Acta - Biomembranes., 2006, 1758(3), 264-279.

[17] Dehsorkhi, A.; Castelletto, V.; Hamley, I.W. Self-assembling amphiphilic peptides. J. Pept. Sci., 2014, 20(7), 453-467.

[18] Zapadka, K.L.; Becher, F.J.; Gomes dos Santos, A. L.; Jackson, S.E. Factors affecting the physical stability (aggregation) of peptide therapeutics. Interface Focus., 2017, 7(6), 20170030.

[19] Panda, J.J.; Chauhan, V.S. Short peptide based self-assembled nanostructures: implications in drug delivery and tissue engineering. Polym. Chem., 2014, 5(15), 44184436.

[20] Mandal, D.; Nasrolahi Shirazi, A.; Parang, K. Self-assembly of peptides to nanostructures. Org. Biomol. Chem., 2014, 12(22), 3544-3561.

[21] Ghadiri, M.R.; Granja, J.R.; Milligan RA, McRee, DE, Khazanovich, N. Selfassembling organic nanotubes based on a cyclic peptide architecture. Nature., 1993, 366(6453), 324-327.

[22] Fernandez-Lopez, S.; Kim, H.; Choi, E.C.; Delgado, M.; Granja, J.R.; Khasanov, A.; Kraehenbuehl, K.; Long, G.;Weinberger, D.A.; Wilcoxen, K.M.; Ghadiri, M.R. 
Antibacterial agents based on the cyclic D, L- $\alpha$-peptide architecture. Nature., 2001, 412(6845), 452.

[23] Alemán, C.; Hamley, I.W.; Reches, M. Peptide hormones and lipopeptides: from selfassembly to therapeutic applications: Peptides: from self-assembly to therapeutic applications. J. Pept. Sci., 2017, 23(2), 82-94.

[24] Caughey, B.; Lansbury, P.T.J. Protofibrils, pores, fibrils and neurodegeneration: separating the responsible protein aggregates from the innocent bystanders. Annu. Rev. Neurosci., 2003, 26(1), 267-298.

[25] Nelson, R. Sawaya, M.R.; Balbirnie, M.; Madsen, A.Ø.; Riekel, C.; Grothe, R.; Eisenberg, D. Structure of the cross- $\beta$ spine of amyloid-like fibrils. Nature. 2005, 435(7043), 773.

[26] Rambaran, R.N.; Serpell, L.C. Amyloid fibrils: abnormal protein assembly. Prion. 2008, 2(3), 112-117.

[27] Reches, M. Casting metal nanowires within discrete self-assembled peptide nanotubes. Science., 2003, 300(5619), 625-627.

[28] Reches, M.; Gazit, E. Formation of closed-cage nanostructures by self-assembly of aromatic dipeptides. Nano Letters., 2004, 4(4), 581-585.

[29] Hamley, I.W.; Dehsorkhi, A.; Castelletto, V.; Furzeland, S.; Atkins, D.; Seitsonen, J.; Ruokolainen, J. Reversible helical unwinding transition of a self-assembling peptide amphiphile. Soft Matter., 2013, 9(39), 9290-9293.

[30] Fu, I.W.; Markegard, C.B.; Chu, B.K.; Nguyen, H.D. The role of electrostatics and temperature on morphological transitions of hydrogel nanostructures self-assembled by peptide amphiphiles via molecular dynamics simulations. Adv. Healthc. Mat., 2013, 2(10), 1388-1400.

[31] Branco, M.C.; Nettesheim, F.; Pochan, D.J.; Schneider, J.P.; Wagner, N.J. Fast dynamics of semiflexible chain networks of self-assembled peptides.

Biomacromolecules., 2009, 10(6), 1374-1380.

[32] Swanekamp, R.J.; Welch, J.J.; Nilsson, B.L. Proteolytic stability of amphipathic peptide hydrogels composed of self-assembled pleated $\beta$-sheet or coassembled rippled $\beta$-sheet fibrils. Chem. Commun., 2014, 50(70), 10133-10136.

[33] Kuang, Y.; Gao, Y.; Xu, B. Supramolecular hydrogelators of N-terminated dipeptides selectively inhibit cancer cells. Chem. Commun., 2011, 47(47), 12625-12627.

[34] McCloskey, A.P.; Gilmore, S.M.; Zhou, J.; Draper, E.R.; Porter, S.; Gilmore, B.F.; $\mathrm{Xu}, \mathrm{B}$; Laverty, G. Self-assembling ultrashort NSAID-peptide nanosponges: multifunctional antimicrobial and anti-inflammatory materials. RSC Adv., 2016, 6(115), 114738-114749.

[35] Song, Y.; Challa, S.R.; Medforth, C.J.; Qiu, Y.; Watt, R.K.; Peña, D.; Miller, J.E.; van Swol, F.; Shelnut, J.A. Synthesis of peptide-nanotube platinum-nanoparticle composites. Chem. Commun., 2004, 4(9), 1044-1045.

[36] Yan, X.; He, Q.; Wang, K.; Duan, L.; Cui, Y.; Li, J. Transition of cationic dipeptide nanotubes into vesicles and oligonucleotide delivery. Angew. Chem. Int. Ed., 2007, 46(14), 2431-2434.

[37] Chen, C.; Pan, F.; Zhang, S.; Hu, J.; Cao, M.; Wang, J.; Xu, H.; Zhao, X.; Lu, J. Antibacterial activities of short designer peptides: a link between propensity for nanostructuring and capacity for membrane destabilization. Biomacromolecules., 2010, 11(2), 402-411.

[38] Veiga, A.S.; Sinthuvanich, C.; Gaspar, D.; Franquelim, H.G.; Castanho, M.A.; Schneider, J.P. Arginine-rich self-assembling peptides as potent antibacterial gels. Biomaterials., 2012, 33(35), 8907-8916. 
[39] Gorbitz, C.H. The structure of nanotubes formed by diphenylalanine, the core recognition motif of Alzheimer's $\beta$-amyloid polypeptide. Chem. Commun. 2006, (22), 2332-2334.

[40] Marchesan, S.; Vargiu, A,; Styan, K. The Phe-Phe motif for peptide self-assembly in nanomedicine. Molecules: J. Syn. Org. Chem. Nat. Prod. Chem., 2015, 20(11), 1977519788.

[41] Adler-Abramovich, L.; Aronov, D.; Beker, P.; Yevnin, M.; Stempler, S.; Buzhansky, L.; Rosenman, G.; Gazit, E. Self-assembled arrays of peptide nanotubes by vapour deposition. Nature Nanotechnology., 2009, 4(12), 849-854.

[42] Wang, M.; Du, L.; Wu, X.; Xiong, S.; Chu, P.K. Charged diphenylalanine nanotubes and controlled hierarchical self-assembly. ACS Nano., 2011, 5(6), 4448-4454.

[43] Zhu, P.; Yan, X.; Su, Y.; Yang, Y.; Li, J. Solvent-induced structural transition of selfassembled dipeptide: from organogels to microcrystals. Chem.: Eur. J., 2010, 16(10), 3176-3183.

[44] Ryu, J.; Park, C.B. High-temperature self-assembly of peptides into vertically wellaligned nanowires by aniline vapor. Adv. Mater., 2008, 20(19), 3754-3758.

[45] Li, Z.; Liu, C.; Ma, S.; Zhang, D.; Yamaguchi, Y. Analysis of the inhibition of nucleic acid dyes on polymerase chain reaction by capillary electrophoresis. Anal. Methods. 2016, 8(11), 2330-2334.

[46] Adler-Abramovich, L.; Reches, M.; Sedman, V.L.; Allen, S.; Tendler, S.J.B.; Gazit, E. Thermal and chemical stability of diphenylalanine peptide nanotubes: implications for nanotechnological applications. Langmuir., 2006, 22(3), 1313-1320.

[47] Krysmann, M.J.; Castelletto, V.; Kelarakis, A.; Hamley, I.W.; Hule, R.A.; Pochan, D.J. self-assembly and hydrogelation of an amyloid peptide fragment. Biochem. (ACS)., 2008, 47(16), 4597-4605.

[48] Reches, M.; Porat, Y.; Gazit, E. Amyloid fibril formation by pentapeptide and tetrapeptide fragments of human calcitonin. J. Biol. Chem., 2002, 277(38), 3547535480 .

[49] De Santis, P.; Forni, E.; Rizzo, R. Conformational analysis of DNA-basic polypeptide complexes: Possible models of nucleoprotamines and nucleohistones. Biopolymers., 1974, 13(2), 313-326.

[50] Chapman, R.; Danial, M.; Koh, M.L.; Jolliffe, K.A.; Perrier, S. Design and properties of functional nanotubes from the self-assembly of cyclic peptide templates. Chem. Soc. Rev., 2012, 41(18), 6023-6041.

[51] Rosenthal-Aizman, K.; Svensson, G.; Undén, A. Self-assembling peptide nanotubes from enantiomeric pairs of cyclic peptides with alternating $\mathrm{D}$ and $\mathrm{L}$ amino acid residues. J. Am. Chem. Soc., 2004, 126(11), 3372-3373.

[52] Whitesides, G.M. Self-assembly at all scales. Science., 2002, 295(5564), 2418-2421.

[53] Hartgerink, J.D.; Granja, J.R.; Milligan, R.A.; Ghadiri, M.R. Self-assembling peptide nanotubes., J. Am. Chem. Soc., 1996, 118(1), 43-50.

[54] Sun, L.; Fan, Z.; Wang, Y.; Huang, Y.; Schmidt, M.; Zhang, M. Tunable synthesis of self-assembled cyclic peptide nanotubes and nanoparticles. Soft Matter., 2015, 11(19), 3822-3832.

[55] Beck, K.; Brodsky, B. Supercoiled protein motifs: the collagen triple-helix and the $\alpha$ helical coiled coil. J. Struct. Biol., 1998, 122(1-2), 17-29.

[56] Fairman, R.; Åkerfeldt, K.S. Peptides as novel smart materials. Curr. Opin. Struct. Biol. 2005, 15(4), 453-463.

[57] Wagner, D.E.; Phillips, C.L.; Ali, W.M.; Nybakken, G.E.; Crawford, E.D.; Schwab, A.D.; Smith, W.F.; Fairman, R. Toward the development of peptide nanofilaments and 
nanoropes as smart materials. Proc. Natl. Acad. Sci. U.S.A., 2005, 102(36), 1265612661.

[58] Potekhin, S.A.; Melnik, T.N.; Popov, V.; Lanina, N.F.; Vazina, A.A.; Rigler, P.; Verdini, A.S.; Corradin, G.; Kajava, A.V. De novo design of fibrils made of short $\alpha$ helical coiled coil peptides. Chem. Biol., 2001, 8(11), 1025-1032.

[59] Hoffman, A.S. Hydrogels for biomedical applications. Adv. Drug Deliv. Rev., 2002, $54(1), 3-12$.

[60] Smith, A.M.; Banwell, E. F.; Edwards, W. R.; Pandya, M.J.; Woolfson, D.N. Engineering increased stability into self-assembled protein fibers. Adv. Funct. Mater., 2006, 16(8), 1022-1030.

[61] Xu, C.; Breedveld, V.; Kopeček, J. Reversible hydrogels from self-assembling genetically engineered protein block copolymers. Biomacromolecules., 2005, 6(3), 1739-1749.

[62] Aggeli, A.; Nyrkova, I.A.; Bell, M.; Harding, R.; Carrick, L.; McLeish, T.C.B.; Semenov, A.N.; Boden, N. Hierarchical self-assembly of chiral rod-like molecules as a model for peptide -sheet tapes, ribbons, fibrils, and fibers. Proc. Natl. Acad. Sci. U.S.A., 2001, 98(21), 11857-11862.

[63] Fishwick, C.W.G.; Beevers, A.J.; Carrick, L.M.; Whitehouse, C.D.; Aggeli, A.; Boden, N. Structures of helical $\beta$-tapes and twisted ribbons: the role of side-chain interactions on twist and bend behavior. Nano letters., 2003, 3(11), 1475-1479.

[64] Aggeli, A.; Bell, M.; Carrick, L.M.; Fishwick, C.W.G.; Harding, R.; Mawer, P.J.; Radford, S.E.; Strong, A.E.; Boden, N. pH as a trigger of peptide $\beta$-sheet self-assembly and reversible switching between nematic and isotropic phases. J. Am. Chem. Soc., 2003, 125(32), 9619-9628.

[65] Lu, K.; Jacob, J.; Thiyagarajan, P.; Conticello, V.P.; Lynn, D.G. Exploiting amyloid fibril lamination for nanotube self-assembly. J. Am. Chem. Soc., 2003, 125(21), 63916393.

[66] Reches, M.; Gazit, E. Casting metal nanowires within discrete self-assembled peptide nanotubes. Science., 2003, 300(5619), 625-627.

[67] Xu, G.; Wang, W.; Groves, J.T.; Hecht, M.H. Self-assembled monolayers from a designed combinatorial library of de novo-sheet proteins. Proc. Natl. Acad. Sci. U.S.A., 2001, 98(7), 3652-3657.

[68] Ashkenasy, N.; Horne, W.S.; Ghadiri, M. Design of self-assembling peptide nanotubes with delocalized electronic states. Small., 2006, 2(1), 99-102.

[69] Chung, H.J.; Park, T.G. Self-assembled and nanostructured hydrogels for drug delivery and tissue engineering. Nano Today., 2009, 4(5), 429-437.

[70] Hong, Y.; Pritzker, M.D.; Legge, R.L.; Chen, P. Effect of $\mathrm{NaCl}$ and peptide concentration on the self-assembly of an ionic-complementary peptide EAK16-II. Colloids Surf. B Biointerfaces., 2005, 46(3), 152-161.

[71] Gao, L.; Wu, J.; Gao, D. Enzyme-controlled self-assembly and transformation of nanostructures in a tetramethylbenzidine/horseradish peroxidase/H2O2 system. ACS Nano., 2011, 5(8), 6736-6742.

[72] Ulijn, R.V.; Smith, A.M. Designing peptide based nanomaterials. Chem. Soc. Rev., 2008, 37(4), 664-675.

[73] Cui, H.; Webber, M.J.; Stupp, S.I. Self-assembly of peptide amphiphiles: from molecules to nanostructures to biomaterials. J. Pept. Sci., 2010, 94(1), 1-18.

[74] Haines, L.A.; Rajagopal, K.; Ozbas, B.; Salick, D.A.; Pochan, D.J.; Schneider, J.P. Light-activated hydrogel formation via the triggered folding and self-assembly of a designed peptide. J. Am. Chem. Soc. 2005, 127(48), 17025-17029. 
[75] Leite, D.; Barbu, E.J.; Pilkington, G.; Lalatsa, A. Peptide self-assemblies for drug delivery. Curr. Top. Med. Chem., 2015, 15(22), 2277-89.

[76] McCarthy, H.O.; McCaffrey, J.; McCrudden, C.M.; Zholobenko, A.; Ali, A.A.; McBride, J.W.; Massey, A.S.; Pentlavalli, S.; Chen, K.; Cole, G.; Loughran, S.P.; Dunne, N.J.; Donnelly, R.F.; Kett, V.L.; Robson, T. Development and characterization of self-assembling nanoparticles using a bio-inspired amphipathic peptide for gene delivery. J. Control. Release., 2014, 189, 141-149.

[77] Massey, A.S.; Pentlavalli, S.; Cunningham, R.; McCrudden, C.M.; McErlean, E.M.; Redpath, P.; Ali, A.A.; Annett, S.; McBride, J.W.; McCaffrey, J.; Robson, T.; Migaud, M.E.; McCarthy, H.O. Potentiating the anticancer properties of bisphosphonates by nanocomplexation with the cationic amphipathic peptide, RALA. Mol.Pharm., 2016, 13(4), 1217-1228.

[78] Lee, J.; Choi, Y.J.; Lim, Y. Self-assembled filamentous nanostructures for drug/gene delivery applications. Expert Opin. Drug Deliv., 2010, 7(3), 341-351.

[79] Wang, Y.; Gong, X. Special oleophobic and hydrophilic surfaces: approaches, mechanisms, and applications. J. Mater. Chem. A., 2017, 5(8), 3759-3773.

[80] Cheetham, A.G.; Zhang, P.; Lin, Y.; Lock, L.L.; Cui, H. Supramolecular nanostructures formed by anticancer drug assembly. J. Am. Chem. Soc., 2013, 135(8), 2907-2910.

[81] Brack, A.; Orgel, L.E. $\beta$ structures of alternating polypeptides and their possible prebiotic significance. Nature., 1975, 256(5516), 383.

[82] Wang, J.; Liu, K.; Xing, R.; Yan, X. Peptide self-assembly: thermodynamics and kinetics. Chem. Soc. Rev., 2016, 45(20), 5589-5604.

[83] Silva, R.F.; Araújo, D.R.; Silva, E.R.; Ando, R.A.; Alves, W.A. L-diphenylalanine microtubes as a potential drug-delivery system: characterization, release kinetics, and cytotoxicity. Langmuir., 2013, 29(32), 10205-10212.

[84] Rong, L.; Qin, S.; Zhang, C.; Cheng, Y.; Feng, J.; Wang, S.; Zhang, X. Biomedical applications of functional peptides in nano-systems. Mater. Today Chem., 2018, 9, 91102.

[85] Li, J.; Li, X.; Kuang, Y.; Gao, Y.; Du, X.; Shi, J.; Xu, B. Self-Delivery Multifunctional Anti-HIV Hydrogels for Sustained Release. Adv. Healthc.Mat., 2013, 2(12), 1586-1590.

[86] Mammadov, R.; Mammadov, B.; Toksoz, S.; Aydin, B.; Yagci, R.; Tekinay, A.B.; Guler, M.O. Heparin mimetic peptide nanofibers promote angiogenesis.

Biomacromolecules., 2011, 12(10), 3508-3519.

[87] World Health Organisation. Cancer: Key Facts 2018. https://www.who.int/newsroom/fact-sheets/detail/cancer. (Accessed May 2, 2019).

[88] Shi, J.; Xiao, Z.; Kamaly, N.; Farokhzad, O.C. Self-assembled targeted nanoparticles: evolution of technologies and bench to bedside translation. Acc. Chem. Res., 2011, 44(10), 1123-1134.

[89] Thundimadathil, J. Cancer treatment using peptides: current therapies and future prospects. J. Amino Acids. 2012, 967347.

[90] Habibi, N.; Kamaly, N.; Memic, A.; Shafiee, H. Self-assembled peptide-based nanostructures: Smart nanomaterials toward targeted drug delivery. Nano Today., 2016, 11(1), 41-60.

[91] Han, L.; Huang, R.; Li, J.; Liu, S.; Huang, S.; Jiang, C. Plasmid pORF-hTRAIL and doxorubicin co-delivery targeting to tumor using peptide-conjugated polyamidoamine dendrimer. Biomaterials., 2011, 32(4), 1242-1252.

[92] Jiang, X.; Sha, X.; Xin, H.; Chen, L.; Gao, X.; Wang, X.; Law, K.; Gu, J.; Chen, Y.; Jiang, Y.; Ren, X.; Ren, Q.; Fang, X. Self-aggregated pegylated poly (trimethylene 
carbonate) nanoparticles decorated with c(RGDyK) peptide for targeted paclitaxel delivery to integrin-rich tumors. Biomaterials., 2011, 32(35), 9457-9469.

[93] Liu, J.; Liu, J.; Xu, H.; Zhang, Y.; Chu, L.; Liu, Q.; Song, N.; Yang, C. Novel tumortargeting, self-assembling peptide nanofiber as a carrier for effective curcumin delivery. Int. J. Nanomedicine., 2014, 9, 197.

[94] Kuang, Y.; Xu, B. Disruption of the dynamics of microtubules and selective inhibition of glioblastoma cells by nanofibers of small hydrophobic molecules. Angew. Chem. Int. Ed., 2013, 52(27), 6944-6948.

[95] Li, J.; Kuang, Y.; Shi, J.; Zhou, J.; Medina, J.E.; Zhou, R.; Yuan, D.; Yang, C.; Wang, H.; Yang, Z.; Liu, J.; Dinulescu, D.M. Enzyme-instructed intracellular molecular selfassembly to boost activity of cisplatin against drug-resistant ovarian cancer cells. Angew. Chem. Int. Ed., 2015, 54(45), 13307-13311.

[96] Araste, F.; Abnous, K.; Hashemi, M.; Taghdisi, S.M.; Ramezani, M.; Alibolandi, M. Peptide-based targeted therapeutics: focus on cancer treatment. J. Control. Release., 2018, 292, 141-162.

[97] Boekhoven, J.; Zha, R.H.; Tantakitti, F.; Zhuang, E.; Zandi, R.; Newcomb, C.J.; Stupp, S.I. Alginate-peptide amphiphile core-shell microparticles as a targeted drug delivery system. RSC Adv., 2015, 5(12), 8753-8756.

[98] Chen, J.; Zou, X. Self-assemble peptide biomaterials and their biomedical applications. Bioact. Mater., 2019, 4, 120-131.

[99] Yishay-Safranchik, E.; Golan, M.; David, A. Controlled release of doxorubicin and Smac-derived pro-apoptotic peptide from self-assembled KLD-based peptide hydrogels. Polym, Adv, Technol., 2014, 25(5), 539-544.

[100] Wang, H.; Feng, Z.; Wu, D.; Fritzsching, K.J.; Rigney, M.; Zhou, J.; Jiang, Y.; Schmidt-Rohr, K.; Xu, B. Enzyme-regulated supramolecular assemblies of cholesterol conjugates against drug-resistant ovarian cancer cells. J. Am. Chem. Soc., 2016, 138(34), 10758-10761. 